AperTO - Archivio Istituzionale Open Access dell'Università di Torino

\title{
On Francesco G. Tricomi's heritage: Archive and miscellany
}

\section{This is a pre print version of the following article:}

Original Citation:

\section{Availability:}

This version is available http://hdl.handle.net/2318/1797798

since 2021-12-22T09:33:34Z

Published version:

DOI:10.1016/j.hm.2021.05.001

Terms of use:

Open Access

Anyone can freely access the full text of works made available as "Open Access". Works made available under a Creative Commons license can be used according to the terms and conditions of said license. Use of all other works requires consent of the right holder (author or publisher) if not exempted from copyright protection by the applicable law. 
Notes and Sources

\title{
On Francesco G. Tricomi’s heritage: Archive and miscellany
}

\author{
Erika Luciano
}

University of Turin, Torino, Italy

\begin{abstract}
After providing a summarised biographical and scientific profile of F.G. Tricomi, we describe the structure and contents of his archive and miscellany, which jointly represent a documentary heritage of great historical importance, as well as one of the major patrimonies of the Department of Mathematics 'G. Peano' at the University of Turin.
\end{abstract}

(C) 2021 Elsevier Inc. All rights reserved.

\section{Sommario}

Dopo aver sinteticamente illustrato il profilo biografico e scientifico di F.G. Tricomi, si descrivono la struttura e la consistenza del suo archivio e della sua miscellanea, che rappresentano un fondo documentario di notevole valore storico, e al contempo uno dei patrimoni più importanti del Dipartimento di Matematica 'G. Peano’ dell’Università di Torino.

(c) 2021 Elsevier Inc. All rights reserved.

Keywords: F.G. Tricomi; Archive; Miscellany; Mathematical patrimony; Documentary heritage

\section{Tricomi's life}

Throughout his life, Tricomi was a major protagonist in Italian mathematics. He played a crucial role in the evolution of several fields of analysis and in strengthening the relations between Italy and the most important scientific centres around the world (Fichera, 1980-1981; Richard, 1982; Schmidt, 1978; Skof, 1999). Various important mathematical objects today bear his name: the Tricomi equation, Tricomi function and even the physical notion Tricomi gases. Names, however, play only a minor role in fully understanding his scientific life, the importance of his actual findings and his heritage.

Born in Naples on May 5, 1897, Tricomi studied at the technical institute and, having graduated at the age of sixteen, enrolled first in the degree course in chemistry, then in physics, at the University of Bologna, moving to Naples sometime between November 1915 and May 1916. Enlisting into the army in the autumn

E-mail address: erika.luciano@unito.it. 
of 1916, he attended a course for junior officers at the Military Academy of Turin and on April 1, 1917 he was sent to the front, initially to the Karst plateau and then to the area of Mounts Grappa and Piave. Despite the war, he still managed to continue his studies and obtained a degree in mathematics in Naples on April 16, 1918, while he was on leave.

After the war, at the beginning of 1920, Tricomi returned to Naples decorated with two War Merit Crosses, and re-established relations with some of his former teachers Ernesto Pascal, Roberto Marcolongo and Gabriele Torelli, who advised him in his early research works and put him in contact with Guido Fubini. In February 1921, at the suggestion of Ugo Amaldi, Tricomi was given his first academic appointment as assistant to Francesco Severi in Padua. The experience at the 'School' of Severi was short-lived, however, because during the early months of 1922 Tricomi was called to Rome, where he obtained a lectureship in algebraic and infinitesimal analysis, entering a high-level academic environment which boasted figures like Vito Volterra, Guido Castelnuovo, Federigo Enriques and Tullio Levi-Civita. The first signs of his interest in partial differential equations, which would become one of his favourite research topics, date to this period.

Winning a competition for the chair of analysis in 1924, Tricomi left Rome for Florence in February 1925. In November of the same year, he moved to Turin as extraordinary professor of algebraic analysis, charged with the teaching of complementary mathematics. Upon his arrival at the Turin faculty, he immediately perceived some tensions among the teaching staff, composed of two groups: the 'Jewish' group, including Gino Fano and Guido Fubini, and the 'vectorialist' one, to which Giuseppe Peano, Tommaso Boggio and Cesare Burali-Forti adhered. ${ }^{1}$ Tricomi veered towards the first team, also because of his solid friendship with Fubini and Alessandro Terracini. Tricomi, however, was also greatly highly appreciated by Peano who, as early as 1925 , invited him to exchange his teaching of complementary mathematics ${ }^{2}$ for infinitesimal calculus. Tricomi would formally take the chair in analysis only from 1932 onward. Director of the Institute of Analysis, of the Special Mathematical Library, the Mathematical Seminar and the annexed journal Rendiconti, between 1948 and 1952 Tricomi was invited to take part in the Bateman manuscript project and spent three years in Pasadena, California, at Caltech. The American experience led to the joint publication, together with Arthur Erdélyi, Wilhelm Magnus and Fritz Oberhettinger, of the text Higher transcendental functions vols. I, II, III [New York 1953-55]. Declared emeritus in 1972, Tricomi was awarded the gold Medal for Mathematics of the National Academy of XL (1956) and the Feltrinelli Prize for Mathematics and Mechanics in 1961. He was also a member of the Academy of Lincei (correspondent from 1951, national from 1962), and president of the Academy of Sciences of Turin for the term 1973-76.

\section{Tricomi's heritage}

Tricomi died in Turin from complications of a stroke, on the evening of November 21, 1978, "while in his studio when he was looking for a publication he wished to consult among his highly ordered miscellany". 3 His wife Susanne Fomm (born in Germany in 1904) had prematurely passed away in July 1959. Being alone, Tricomi indicated as his heir and executor of his estate colleague Gaetano Fichera, full professor of

\footnotetext{
1 The names 'Jewish' and 'vectoralist' were introduced by Tricomi to casually characterise two opposite groups of colleagues in Turin's mathematics department during the 20s and 30s. The origin derives from their constitution: the 'Jewish group' consisted of experts in algebraic geometry, coincidentally all of Jewish origin. The members of the 'vectorialist group' were pupils of Peano, devoted to research in vector calculus.

2 The teaching of complementary mathematics deals with three main subjects: history of mathematics, didactics of mathematics, and foundations of mathematics.

3 (Fichera, 1979a, p. 469): "mentre nel suo studio cercava, fra la sua ordinatissima miscellanea, una pubblicazione che desiderava consultare".
} 
analysis at Rome La Sapienza, "the son he would ever want and could never have". ${ }^{4}$ Fichera, ${ }^{5}$ who with his wife Matelda had assisted Tricomi until the end with true affection and self-denial, personally took care of the dispersal of Tricomi's estate:

We had to sojourn in Turin for six months, as the task of examining the whole house of Tricomi, in which he had kept every detail of his long life, was quite complex. While Gaetano looked at the documents, the books, the offprints, I had to take care of everything else; I still remember how challenging and difficult it was. Many of us have a sort of passion for preserving memories, but certainly without reaching the exaggerations that we had to face in Tricomi's house! (Fichera Colautti, 2006, p. 99). ${ }^{6}$

Both the archive and the collection of offprints and reprints were acquired by the Department of Mathematics of Turin, apparently in $1979,{ }^{7}$ and were stored in the director's office at the Institute of Analysis, where they remained until recent years. Apparently, these materials were neglected on shelves for decades, except for a small contribution entitled Massime e pensieri tratti da un quaderno di Francesco G. Tricomi published by Fichera in a journal of mathematics education (Fichera, 1979b). Tricomi's manuscripts were not taken into consideration by the editors of his selected works (Tricomi, 2011). In the summer of 2017, during some building renovations at the Department of Mathematics, the author of this contribution was invited to the office of Prof. Fulvia Skof, who succeeded Tricomi as director of the Institute of Analysis in 1979, and thus had access for the first time to Tricomi's patrimony. In an initial stage of work, the manuscripts by Tricomi were separated from the rest of Skof's papers, with which they had become mixed over the years. A first provisional inventory of these documents was then published in (Luciano and Rosso, 2018).

Built up between 1913 and 1978, the Tricomi archive consists of 12 folders of student notes, 753 manuscripts, 20 manuscript versions of books, and a collection of institutional and family papers. ${ }^{8}$ A very meticulous man, Tricomi himself roughly divided the materials into two series:

- Archivio diverso A (Mixed papers Archive A): these are the oldest manuscripts, pertaining to his first mathematical studies in the period from summer 1915 to December 1919 and to the first five publications by Tricomi (years 1916-17)

- Protocolli scientifici S (Scientific Protocols S): these cover the entire activity and production of Tricomi, from his sixth publication Sulle serie di funzioni di linee [Napoli Rend. (3) 26, 1920, 160-169] onward.

The Protocolli (hereafter protocols) are basically document folders. In each of them, Tricomi collected everything that referred to an article, book, conference, university course, book review, or talk, etc. From this point of view, our work has really been minimal because classifying, numbering, ${ }^{9}$ title, date and place of production, foliation and date of cataloguing of almost all the files are to be attributed to Tricomi himself and have been maintained. The few non-catalogued documents were ordered in chronological sequence.

\footnotetext{
4 (Fichera Colautti, 2006, p. 98): "il figlio che avrebbe voluto e che non aveva mai potuto avere".

5 Gaetano Fichera (1922-1996), a pupil of Mauro Picone, taught at the Universities of Trieste and Rome. He worked in mathematical analysis, linear elasticity, partial differential equations and several complex variables. Matelda Colautti married Gaetano Fichera in 1952. At that time it was common in Italy, for a women, to add the surname of the husband to her proper surname.

6 "Dovemmo fermarci a Torino per sei mesi, in quanto molto complesso fu il compito di esaminare tutta la casa di Tricomi, nella quale egli aveva conservato ogni minimo dettaglio della sua lunga vita. Mentre Gaetano si occupava dei documenti, dei libri, degli estratti, io dovetti occuparmi di tutto il resto; ancora ricordo come sia stato impegnativo e difficile. Molti di noi hanno un po' la passione di conservare ricordi, ma certo non raggiungendo gli estremi che dovemmo constatare in casa Tricomi!"

7 No official documentation of the acquisition of the patrimony was found, either in Tricomi's archive or in the historical archive of the University of Turin. Through a letter from the University of Turin to Fichera, dated 6.11.1981, it seems that the process of succession had already been closed at that date.

8 These documents mainly concern Tricomi's work as director of the Institute of Analysis and include the Institute's expense records in the years 1952-1965, a collection of tables, some portraits, photographs and personal items.

9 Evidently the numbers of the protocols do not coincide with those of the many lists of Tricomi's publications.
} 
The cataloguing and reordering of the protocols went on until the last period of Tricomi's life. In prot. no. 731, Aggiornamento voci 1978, for example, when reviewing the entry Matematica he had written for the Italian Encyclopedia, Tricomi wondered about the inclusion of some sentences on the four-colour theorem and noted: "from an interview with Beniamino Segre on February 14, 1976 it would result that the abovementioned conclusions are wrong. I therefore decide to renounce this 'update'. February 16, 1976". ${ }^{10}$

The miscellany, amassed between 1914 and 1978, consists of 11,260 printed items; the most recent checklist was concluded on October 30, 1972. Much of the material is heavily annotated. The manuscript entitled Sviluppo della Collezione Opuscoli (Development of the Booklets Collection) gives a detailed overview of any additions in the first twenty-five years: the number of extracts collected each year is recorded between March 1917 and 1942. The trend grew constantly, passing from the 17 offprints acquired in 1917 to the 435 collected in 1936. There were approximately 190 new pieces introduced per year. Some data are surprising: the 245 new entries in 1941 and, even more, the 257 booklets amassed in 1942 when Turin was already under heavy allied bombing. The miscellany was also arranged by Tricomi. The manuscript Quadro di Classificazione degli opuscoli e degli appunti scientifici e bibliografici (Synopsis and Classification of offprints and scientific-bibliographical notes, December 2, 1926) explains the reasoning. Extracts were divided into five macrosubject-areas, each of which comprised several subheadings (see Table 1).

A card catalogue cabinet is still preserved today, with four drawers ordered alphabetically by author in two series: A-G, H-Z, A-O, P-Z. The cards are all handwritten, mostly by Tricomi himself. Many of the authors' cards are duplicated because the first two drawers include publications up to about 1948, and the second two the most recent ones, up to 1978. The cards have been updated up to the end: for example on the card ERDÉLYI, who died in December 1977, the symbol $\dagger$ appears next to his name. On many cards a number and a letter occur next to some titles: they refer to the thematic classification adopted by Tricomi in the first period of his scientific activity (1918-1932) and described in the aforementioned manuscript Quadro di Classificazione.... ${ }^{11}$ For example, on the card FUBINI the offprint no. 1640, Sugli invarianti di un'equazione di Laplace [Boll. UMI 7, 1928, 175-177] is labelled A13, while no. 1642, Le trasformazioni di Laplace, di Lévy e di Moutard per le ipersuperficie [Rendiconti Accad. d. L. Roma (6) 8, 1928, 265-268] is classified as B4.

It is quite rare for a mathematician to classify his manuscripts and library jointly and at the same time. Tricomi not only did so, but also left an important meta-referential device: his Schedario personale (Personal card index). This consists of another drawer, containing 503 handwritten cards, on which Tricomi annotated bibliographic references, excerpts of readings that could be useful in his studies, comments and memoranda. On the front of each card there is the subject heading (name of the author, title of the article or book, and its number order in Tricomi's library); on the back there are notes about the pivotal elements of the work, proofs completed or redone by Tricomi, and connections with other texts. The manuscript Classificazione personale delle schede bibliografiche describes the organisation of the card index. This classification concerns only the cards of the Schedario personale and is not to be confused with the previous one, which instead concerned the classification of miscellany. Thirty-nine cards are out of order, probably because Tricomi was using them at the time he passed away. The last section consists of sixtythree cards, each of which relates to a single book on partial differential equations. By cross-checking the data on this personal card index with examination of the manuscripts, it is possible to identify (with extreme precision) Tricomi's readings at a given moment, what he considered to be the heritage of knowledge of a certain sector of study in a given period, and how his opinions changed over time, on the basis of both his research practices and research partnerships. See Table 2.

\footnotetext{
10 "Da un colloquio avuto il 14.2.76 con Beniamino Segre risulterebbe che le conclusioni di cui sopra sono erronee. Decido perciò di rinunciare a questo 'aggiornamento'. 16.2.1976".

11 Tricomi claims to have abandoned this type of classification on April 6, 1932, while cataloguing the offprint no. 2200.
} 
Table 1

Synopsis and classification of offprints and scientific-bibliographical notes.

\begin{tabular}{|c|c|c|c|c|c|}
\hline A Analysis & $\begin{array}{l}\text { A1 Number theory } \\
\text { A2 Determinants } \\
\text { A3 Algebra } \\
\text { A4 Series and other algorithms. } \\
\text { Iteration } \\
\text { A5 Differential and integral calculus } \\
\text { A6 Calculus of finite differences, } \\
\text { interpolation and numerical } \\
\text { quadratures. Numerical calculus } \\
\text { A7 Sets, Lebesgue integrals and other } \\
\text { generalised integrals, with their } \\
\text { applications } \\
\text { A8 Series and approximation theory. } \\
\text { Asymptotic expansions } \\
\text { A9 Complex functions } \\
\text { A10 Special functions and definite } \\
\text { integrals } \\
\text { A11 Group theory. Linear substitutions } \\
\text { A12 ODE } \\
\text { A13 PDE. Potentials } \\
\text { A14 Integral equations and functional } \\
\text { analysis } \\
\text { A15 Calculus of variations } \\
\text { A16 Absolute differential calculus }\end{array}$ & B Geometry & $\begin{array}{l}\text { B1 Foundations and elementary } \\
\text { geometry } \\
\text { B2 Analytic, projective and } \\
\text { descriptive geometry } \\
\text { B3 Algebraic geometry } \\
\text { B4 Differential geometry } \\
\text { B5 Analysis situs } \\
\text { B6 Vectors geometric calculus, } \\
\text { generalised algebras, Riemann } \\
\text { matrices, Eisenhart matrices }\end{array}$ & $\begin{array}{l}\text { C Applied } \\
\text { Mathemat- } \\
\text { ics and } \\
\text { Physics }\end{array}$ & $\begin{array}{l}\text { C1 Mechanics } \\
\text { C2 Mathematical physics } \\
\text { C3 Astronomy and geodesy } \\
\text { C4 Theoretical and experimental } \\
\text { physics } \\
\text { C5 Theory of relativity } \\
\text { C6 Probability calculus, actuarial } \\
\text { mathematics and statistics } \\
\text { C7 Engineering and technology } \\
\text { C8 Physics of the Earth. Meteorology } \\
\text { C9 Applications to natural sciences }\end{array}$ \\
\hline $\begin{array}{l}\text { D History, } \\
\text { Philosophy, } \\
\text { etc. }\end{array}$ & $\begin{array}{l}\text { D1 History of mathematics, history of } \\
\text { other sciences } \\
\text { D2 Philosophy and pedagogy. Scientific } \\
\text { erudition. Cultural issues related to } \\
\text { scientific teaching } \\
\text { D3 Reviews, biographies and } \\
\text { bibliographies, reports } \\
\text { D4 General contents }\end{array}$ & E Diversi & $\begin{array}{l}\text { E1 Chemistry and natural sciences. } \\
\text { Pathology } \\
\text { E2 Moral sciences and non-scientific } \\
\text { topics } \\
\text { E3 General university and cultural } \\
\text { issues }\end{array}$ & & \\
\hline
\end{tabular}

A3 Algebra
A4 Series and other algorithms
Iteration

A5 Differential and integral calculus

A7 Sets, Lebesgue integrals and other

generalised integrals, with their

A8 Series and approximation theory.

integrals

A12 ODE

DE. Potentials

analysis

A15 Calculus of variation

D2 Philosophy and pedagogy. Scientific

Cultural issues related to

Reviews, biographies and 
Table 2

Classification of cards in Tricomi's Personal card index.

\begin{tabular}{ll}
\hline A Differential equations & $\mathbf{3 8}$ cards \\
\hline 1 Ordinary Differential Equations & 1.1 Linear equations \\
& 1.2 Non-linear equations \\
& 1.3 Eigenvalue problems \\
& 1.4 Asymptotic methods \\
& 1.5 Topological methods \\
& 1.6 Special equations
\end{tabular}

2 First order partial differentia equations. Method of characteristics and formal theory of higher-order partial differential equations and their systems 3 Second order partial differential equations

3.1 Elliptic type. Harmonic functions

3.2 Hyperbolic type

3.3 Parabolic type

3.4 Mixed type

4 High-order partial differential equations 5 Group theory and differential equations; research of geometric interest 6 Finite difference equations

$B$ Integral equations and functional
analysis

1 Integral equations

3 Calculus of variations

4 Series expansions and approximation of functions

5 Other questions (Functional equations, topology of function spaces, etc.)

\section{Special functions}

1 Elementary functions and algebraic functions

2 Elliptic functions, elliptic integrals \&C

3 Polynomials

3.1 General theory

3.2 Special Classes

4 Hypergeometric functions

\section{5 cards}

\section{3 cards}

1.1 Normal linear equations

1.2 Singular linear equations

1.3 Non-linear equations

1.4 Special equations

2.1 Laplace Transform (Symbolic method)

2.2 Other

4.1 Fourier series (in the strictest sense)

4.2 Other function series

4.3 Approximation and Interpolation of Functions

\subsection{Gauss's} hypergeometric functions 4.2 Classical confluent functions (Laguerre polynomials excluded)
3.21 Legendre polynomials

3.22 Other Jacobi polynomials

3.23 Laguerre-Hermite polynomials

3.24 Other special polynomials

4.11 Spherical functions

4.21 Bessel functions \&C
4.22 Incomplete gamma function

4.221 Exponential integral function, Integral sine function, etc.

4.222 Error functions \&C

4.23 Parabolic cylinder functions

4.24 Other particular cases 
Table 2 (continued)

\begin{tabular}{ll}
\hline C Special functions & $\mathbf{2 3 5}$ cards \\
\hline & $\begin{array}{l}4.3 \text { Generalised } \\
\text { hypergeometric functions } \\
\text { pFq, etc. }\end{array}$ \\
$\begin{array}{ll}5 \text { Euler's Gamma function \&C and } \\
\text { related functions of number theory } \\
6 \text { Other special functions (Lamé etc.) }\end{array}$ \\
$\begin{array}{l}\text { D Probability calculus and relevant } \\
\text { matters }\end{array}$ & $\mathbf{5}$ cards \\
\hline
\end{tabular}

1 Probability theory in general

2 Mathematical statistics

3 Theory of errors

4 Theory of Games

5 Financial mathematics, Mathematical

economics \&C

6 Applications

\section{E All the rest}

\section{0 cards}

1 Analytic functions in general and their special classes

2 Theory of functions of real variables

2.1 Sets and their measures

2.2 Modern theory of integration

2.3 Differential and integral calculus

2.4 Remaining questions

3 Algebra

3.1 Classic Algebra (theory of equations)

3.2 Vectors, tensors, matrices, etc.

4 Number theory

3.3 Modern Algebra (Group Theory included)

4.1 Elementary number theory

5 Theory of series and other infinite

4.2 Analytic and probabilistic number theory

algorithms

6 Geometry (Absolute differential

calculus \&C included)

7 Mechanics and Physics

8 Numerical, Mechanical And graphical

calculus. Numerical tables

9 Applications

9.1 in physics and mechanics

9.2 Elasticity and Resistance of the materials

9.3 Fluid mechanics

9.4 Electronic and Radio Engineering

9.5 Other applications

10 Asymptotic methods in general.

Inequalities

11 Foundations, History and Philosophy.

Didactic questions

12 What escapes the previous

classification

Tricomi's archive of manuscripts is more or less complete. Strangely, the only manuscript mentioned in the past, i.e. the notebook Massime e pensieri of which Fichera published some passages in 1979, is missing. In the series Protocolli S, seventy-nine dossiers are missing (nos. 483-560) and they are all manuscripts from the times Tricomi spent in Pasadena or those immediately following his return to Turin. Also missing 
are the manuscripts of 31 of Tricomi's 346 publications, and in particular those of his last six works, which appeared in the years 1976-1978. As far as the manuscript versions of the volumes are concerned, there are two works missing: the manuscript of the book Algebra per i licei (Tricomi, alias Terracini, 1940), a textbook which was written entirely by Terracini but which was published under the name of Tricomi due to the racial laws of 1938, and the manuscript of his autobiography La mia vita di Matematico.

The Miscellany section also is almost complete, with missing work amounting to around 5\% of the patrimony. This is generally due to offprints being taken for study and research purposes by Tricomi himself or some of his colleagues, and never returned (the practice of borrowing pieces from this collection unfortunately seems to have been allowed, or at least tolerated, for a very long time).

On the contrary, the library and correspondence are now missing. The books might have been kept by Fichera, or they might have flowed into the library of the Institute of Analysis and, upon its suppression in 1982, possibly ended up in the Special Mathematics Library. ${ }^{12}$ Inexplicable, indeed, is the fate of Tricomi's correspondence, which was mostly lost. According to Fichera, Tricomi had woven a large network of international relationships because:

although he was, throughout his life, an isolated person, due to his great independence of character, the extreme - at times even embarrassing - sincerity of behaviour, the innate inability to propose or accept compromises, he enjoyed the esteem and deep respect of the whole Italian mathematical community and [...] abroad, especially in the United States and the Soviet Union, he was considered a legendary figure, one of the greatest mathematicians of this century (Fichera, 1979a, p. 471-472). ${ }^{13}$

That Tricomi entertained correspondence exchanges with dozens of Italian and foreign colleagues, scientific societies, academies, research institutions, publishers and editors of journals, is beyond doubt. However, almost no traces of Tricomi's correspondence with Fubini, Levi-Civita, Terracini, E. Persico, W. Blaschke, F.P. Cantelli, Erdélyi, O. Perron, R. Sauer, or P.B. Amirà (correspondence referred to in his writings), ${ }^{14}$ have been found so far. The few exceptions are of three types:

- some letters, from Persico, B. Segre, M. Kraft, E. Marchionna etc. that were inserted into specific protocols, because of the specific work that had caused them; ${ }^{15}$

- a significant number of the letters that Tricomi received or wrote in his role as director of the Special Mathematics Library (1938-1948, 1964-1971), which survived because they were preserved not in his personal archive, but among the papers of the Special Mathematics Library institutional archive;

- some dozens of letters that were saved because in the second post-war period, from approximately 1948 onward, Tricomi began to take notes on the backs of letters he had received.

\footnotetext{
$\overline{12}$ In spite of careful research in the Special Mathematics Library I did not find the acquisitions ledger. Tricomi's inscriptions are present in about forty books.

13 "Pur essendo egli stato, durante tutta la sua vita un isolato, per la grande indipendenza di carattere, la estrema - a volte addirittura imbarazzante - sincerità di comportamento, la incapacità costituzionale a proporre $\mathrm{o}$ ad accettare compromessi, godeva della stima e del rispetto profondo di tutta la comunità matematica italiana e [...] all'estero, specie negli Stati Uniti e nella Unione Sovietica, egli era considerato una figura leggendaria, uno dei più grandi matematici di questo secolo”.

14 See for ex. Tricomi (1967), p. 7, 4, 12, 20, 23, 39, 50, 52, 59, 65, 74, 90, 97, 103.

15 For example, letters from Kraft to Tricomi dated 3.6.1943, 21.6.1943, 15.7.1943, 23.7.1943, 26.8.1943, and catalogued with the records 6478CS, 6494CS, 6512CS, 6550CS were found in the envelope containing the materials for the second edition of the treatise Funzioni ellittiche; a letter from Persico, dated 21.2.1954 (2318CS) in prot. no. 570, Sull'equazione differenziale $\varphi^{*}+\mathrm{htsin} \varphi=\mathrm{M}$; a letter from Marchionna, 26.2.1960 in prot. no. 606, Su la Matematica degli ultimi trent'anni (Articoli d'enciclopedia e conferenze). The dossier Carte varie CONARM [COmitato NAzionale Ricercatori Matematici] includes drafts of letters by Tricomi (10872SP, 10870 SP, 778SP) and letters from B. Segre (4655SP), G. Pompilj (4654SP), A. Ghizzetti (4653SP), L. Geymonat (4652SP), E. Togliatti (4651SP), E. Martinelli (4650SP), C. Miranda (4647SP), G. Medici (10870SP), E. Magenes (4463SP), Lombardo (4605 SP and 4599 SP), E. Perrucca (4514AS) and M. Picone (4516SP), concerning the proceedings of the conference Problemi di struttura della matematica italiana (Bologna, February 28-29, 1960).
} 
Since all the letters we have found bear a number and an acronym, it is highly probable that Tricomi also catalogued his correspondence. The inventory records were assigned immediately, often on the same day he received the letters. We believe the acronyms can be interpreted as follows:

- CS - Corrispondenza Scientifica (Scientific Correspondence);

- Un - Università (University)

- AS - Accademie Scientifiche (Scientific Academies)

- AE - Accademie Estere (Foreign Academies)

- SP - Società Professionali (Professional Societies)

- Es - Estero (International).

\section{The heuristic value of Tricomi's heritage}

The heuristic value of patrimonial studies has been emphasised by recent literature in the realms of material and cultural history of science (Adell and Pourcher, 2011; Boudia et al., 2010). Tricomi's legacy is no exception inasmuch as its documents present a true variety of elements of interest, both from biographical and mathematical points of view.

\subsection{Biography}

As previously mentioned, in 1967 Tricomi published a sort of autobio-bibliography. Works also exist dedicated to specific aspects of his impressive production, his influence on analysis and his important contribution towards the present development of pure and applied mathematics (Fichera, 1985; Dong and Chi, 1986; Mikhlin, 1986; Tricomi's ideas and contemporary applied mathematics, 1997). However, the files in Tricomi's archive give authoritative information on little-known or completely obscure episodes of his life.

For example, the manuscripts classified as Appunti da studente, i.e. the lecture notes of the courses attended by Tricomi in Bologna and Naples, and the notes in functional analysis, prior to the writing of his degree thesis Sulla teoria delle funzioni di linee, offer an almost complete picture of Tricomi's mathematical training and research apprenticeship. ${ }^{16}$

Similarly, the manuscripts of the series Archivio Diverso $A$ inform us about Tricomi's early extensive studies in different fields: function iteration, meteorology, astronomical refraction, calculations of the sun's zenith distance and of the movement of the planets in relation to the earth. The collection includes the drafts of his first articles that appeared in Battaglini's Giornale di Matematiche and numerous manuscripts from the period of the World War 1, when Tricomi carried out field-work research in ballistics and geodesy. Dozens of manuscripts are dedicated to topographical surveys of the areas in which he was militarily engaged; others include angles measurements and calculus relating to the construction of shooting tables for mortar systems.

Furthermore, Tricomi's time in Turin was affected by World War II and his work was interrupted for a time. An outspoken opponent of the fascist regime, Tricomi refused to enroll in the party until 1933 and, after the promulgation of the racial laws, did his utmost to help Jewish colleagues. He did this by providing them with books and journals, by offering Terracini the chance to publish a textbook of algebra for high schools by using his, that is Tricomi's, name (Tricomi, alias Terracini, 1940), and by holding a lecture

\footnotetext{
16 Notes, taken in unpolished copy and then rewritten, refer to the courses of analytic geometry, acoustics-optics, electricity, algebra, calculus, descriptive geometry, projective geometry, rational mechanics, advanced mechanics (Fourier series), higher geometry and advanced analysis. However, the notes that Tricomi took during his first year of university studies in Bologna while attending Federigo Enriques' lectures no longer exist.
} 
at the Mathematical Seminar, in the middle of the racial persecution era, devoted to the methodological tenets promoted by the Jewish C. Segre. In the autumn of 1942, Tricomi was forced to leave Turin and took refuge in the Waldensian valleys. After the armistice, he had to escape Nazi-fascist retaliation and reached Rome, where he lived in hiding for over eight months, helping Castelnuovo, Enriques and many others to escape the roundups. Unpublished protocols nos. 437, Riflessioni sul centenario galileiano and 439, Due articoli d'argomento etico-religioso make clear Tricomi's proactive anti-fascism, together with his mathematical studies during the Roman period [no. 450, Considerazioni matematiche varie durante il mio esilio romano], his contacts with the Roman Institute of Mathematical Culture [no. 451, Finalità $e$ caratteri dell'insegnamento della matematica], and finally his engagement in the cultural reconstruction of the country after the fall of the regime [no. 445, Quale dovrà essere, domani, il nostro compito?].

Finally, the manuscripts in Tricomi's archive let us investigate two further aspects of his scientific biography, only partially documented by his La mia vita di Matematico, namely the contributions to debates on the teaching of mathematics and his activity as a lecturer at local, national and international levels, to which he made particularly lively contributions in the last years of his life.

As far as the first aspect is concerned, Tricomi was a talented teacher and had a deep interest in expository work. Dozens of his students and colleagues lauded the style of his teaching; his treatises for graduate or advanced undergraduate levels were widely appreciated and translated into German, English, French and Russian. Tricomi's archive includes a vast range of sources for twenty of his books: ${ }^{17}$ preliminary versions, annotated copies, supplementary materials for reprints, translations, new editions and proofs. Moreover, the drafts of many of Tricomi's fine lectures are preserved, like those on Problemi matematici dell'aerodinamica transonica held at the National Institute of High Mathematics in 1963 (prot. no. 635), at the Corsi d'aggiornamento and Corsi di Cultura Matematica for mathematics secondary school teachers in 1960, 1961, 1963 and 1969 (prots. nos. 610, 615, 619 and 703). And there is more: exercises, tests for written exams and competitions, notes and summary schemes for the degree theses which Tricomi advised. The most interesting aspects, however, emerge from those papers where Tricomi comments on the methodological tenets that motivated his teaching, both in general and on specific subjects such as the modern theory of integration, functional spaces, special functions, etc. Such manuscripts convey a more nuanced and complete image of Tricomi in his roles as teacher, advisor and trainer of prospective teachers. Protocols nos. 70, Questioni didattiche relative all'introduzione dei numeri reali, 182 Intuizione e logica nella scoperta matematica, 146 Some features on the Italian Universities, and 408 Presentazione della nuova edizione delle mie "Lezioni" alla Regia Accademia delle Scienze di Torino particularly stand out from this point of view.

Some of the activity of the older Tricomi as a guest lecturer in Italy and abroad, evident from protocols from 1965-1978, is particularly striking. Tricomi, in fact, was generally considered a brilliant speaker, but often provocative, sarcastic and even "extremely mean". ${ }^{18}$ His character was defined as "hateful" ("infame") by Emma Castelnuovo and others. In particular, some of his late talks caused a sensation due to his comments on Peano, whom he alleged to be "indecorous" (indecoroso) in his teaching of analysis, or about the vectorialist group, allegedly consisting of men "of sub-proletarian origins and left-wing political ideas, promptly relegated to the attic after the rise of fascism". ${ }^{19}$ The archive includes many rough drafts and

\footnotetext{
17 Lezioni di Analisi Matematica for the basic curricula (1st ed. in 1925, ninth in 1966), and the treatises on analytic functions (1937), elliptic functions (1937), orthogonal series of functions (1948), confluent hypergeometric functions (1954), integral equations (1957), special functions (1959), ordinary differential equations (1st ed. in 1948, fourth in 1967) and partial differential equations (1954).

18 (Bravo, 1975, 40): “eccezionalmente meschino".

19 "di origini sotto-proletarie e di idee politiche di sinistra, poi subito messe in soffitta dopo il consolidamento del fascismo". I matematici fuori della matematica [1961, prot. no. 613, unpublished], Conservatori e progressisti nella matematica di ieri e di oggi (Tricomi, 1965, prots. nos. 653 and 660), Matematici torinesi dell'ultimo secolo (Tricomi, 1968, prot. no. 687), Uno sguardo
} 
first versions of talks of a historical and didactic content that Tricomi delivered in national conferences, at the Mathematical Seminar of the University and Polytechnic of Turin, in meetings for teachers, and at the Turin Academy of Sciences, during his presidential term. Reading the texts of these lectures in Tricomi's own words reveals the lucidity with which he stigmatised the defects of the Italian school system and the problems with the new trends in maths education during the 60s [see prots. nos. 633, Riflessioni sull'insegnamento della matematica nelle scuole secondarie, 648 Problemi d'optimum sulla demolizione della Scuola, 684 Questioni attuali sull'insegnamento matematico nelle scuole secondarie, and 713 Ricordo di Federigo Enriques, nel centenario della nascita]. However, reading these texts also gives us the means to define the limits of Tricomi's historical conception of mathematics, of mathematicians and of the Turin cultural environment in particular.

\subsection{Mathematical content}

Tricomi's published mathematical output consists of over 300 works, mostly characterised by a preference for concrete and applied problems, which cover a large variety of topics: partial differential equations, special functions, functional transformations, singular integrals, asymptotic evaluations, pseudodifferential operators, functional transforms (by Bessel, Gauss, Hankel), incomplete gamma function, confluent hypergeometric functions, Legendre polynomials, numerical calculus, probability theory and its applications to number theory, statistics and its applications including the first quantitative theory of the phenomenon of bacterial resilience. One particularly well-known study looks at a partial differential equation of mixed type $y u_{x x}+u_{y y}=0$ (Tricomi, 1923). As Theodore von Kármán and Felix Frankl would show, in fact, this provides a first degree linear transonic approximation of the non-linear equation that occurs in the study of the motion of a body which, passing from a subsonic to a supersonic speed, moves with a speed close to that of sound. Tricomi's 1923 paper gave impetus to important developments, both theoretical - in the field of degenerate elliptic equations and singular integral equations - and applicative, in the framework of transonic aerodynamics, so much so that since then the gases whose behaviour is described by this equation are called Tricomi's gases.

Aware of the particular relevance of some of his contributions, Tricomi himself created in his archive three very large special folders, containing preparatory notes, manuscripts submitted for publication, revisions and drafts relating to specific subjects or research projects. The first of these subject files, chronologically arranged, includes the Ricerche sul problema del disco e equazioni integrali con asterisco (Research on the disc problem and integral equations with asterisk), the second encompasses the studies on the Equazioni a punti critici fissi (Equations with fixed critical points) and the third is entirely dedicated to the famous Ricerche sulle equazioni di tipo misto (Research into mixed-type equations). This last folder, which includes 20 protocols, for over 1280 folia, was rearranged by Tricomi twice, the last probably in 1954 on the occasion of the conference Sullo stato attuale della teoria delle equazioni a derivate parziali (Tricomi, 1955, prot. no. 572). In addition to the usual cataloguing number (for example prots. nos. 81, 83, 84 , etc.), each document in these three special folders has an order number $(1,2,3, \ldots)$ which enables the identification of the chronological concatenation among the manuscripts, and tracks in detail the research path that Tricomi travelled in order to reach his most important results. Finally, intriguing historical material exists in the form of the narratives of protocols nos. 248, Della mia attività scientifica e didattica nel triennio 1925-27, 376 A quarant'anni, 392 Elenco delle pubblicazioni 1916-1938 e cenni sul contenuto di alcune di esse, and 471 Preistoria delle mie recenti ricerche sul comportamento asintotico delle funzioni ipergeometriche confluenti e dei polinomi di Laguerre.

allo sviluppo della matematica in Italia nel primo secolo dello stato unitario (Tricomi, 1969, prot. no. 695), Ricordi di mezzo secolo di vita torinese (Tricomi, 1974, prot. no. 722), Guido Fubini e la scienza delle costruzioni (Tricomi, 1975, prot. no. 729). Tricomi was fiercely anti-fascist; in the afore-quoted passage he referred to two colleagues, Tommaso Boggio and Cesare Burali-Forti, who had strongly supported the regime since the very beginning. 
As a conclusion, the preceding pages provide simply a few examples to illustrate the historical value of Tricomi's heritage, but hopefully they are sufficient to show the potential of this archive to clarify the evolution of Tricomi's mathematical and methodological thought from 1923 to 1978 and to better understand some aspects in his scientific biography.

\section{References}

Adell, N., Pourcher, Y., 2011. Transmettre, quel(s) patrimoine(s)? Autour du patrimoine culturel immatériel. Michel Houdiard éditeur, Paris.

Boudia, S., Rasmussen, A., Soubiran, S., 2010. Patrimoine et communautés savantes. PUR, Rennes.

Bravo, G.M., 1975. Una 'nobile' accademia e il suo poco nobile presidente. Nuova Soc. III 50, 40-41.

Dong, G.C., Chi, M.Y., 1986. Influence of Tricomi’s mathematical work in China. In: Rassias, J.M. (Ed.), Mixed Type Equations. Teubner, Leipzig, pp. 105-111.

Fichera, G., 1979a. Francesco Giacomo Tricomi. Atti Accad. Naz. Lincei, Rend. Cl. Sci. Fis. Mat. Nat. (8) 66, 467-483.

Fichera, G., 1979b. Massime e pensieri tratti da un quaderno di Francesco G. Tricomi (1897-1978). Archimede 31, $15-16$.

Fichera, G., 1980-1981. Francesco Giacomo Tricomi. Atti Accad. Sci. Torino, Cl. Sci. Fis. Mat. Nat. 114, 37-48.

Fichera, G., 1985. Francesco Giacomo Tricomi. In: Rassias, J.M. (Ed.), Mathematical Analysis. Teubner, Leipzig, pp. 6-31.

Fichera Colautti, M., 2006. ... ed è subito sera. La lunga, brevissima vita di Gaetano Fichera (privately printed book).

Luciano, E., Rosso, L., 2018. L'archivio e la biblioteca di Francesco G. Tricomi. Riv. Stor. Univ. Torino VII 1, $105-327$.

Mikhlin, S.G., 1986. On Tricomi’s works on integral equations. In: Rassias, J.M. (Ed.), Mathematical Analysis. Teubner, Leipzig, pp. 195-204.

Richard, U., 1982. Francesco Giacomo Tricomi. Boll. UMI (6) 1, 159-170.

Schmidt, H., 1978. Francesco Giacomo Tricomi. 5.5.1897-21.11.1978. https://badw.de/fileadmin/nachrufe/Tricomi\% 20Francesco\%20Giacomo.pdf.

Skof, F., 1999. Francesco Giacomo Tricomi. In: Roero, C.S. (Ed.), La Facoltà di Scienze Matematiche Fisiche Naturali di Torino 1848-1998, Vol. 2. I docenti. DSSP, Torino, pp. 598-602.

Tricomi's ideas and contemporary applied mathematics. Convegno internazionale in occasione del centenario della nascita di Francesco G. Tricomi. Roma, 28-29 novembre - Torino, 1-2 dicembre 1997. Accademia nazionale dei Lincei, Roma, 1998.

Tricomi, F.G., 1923. Sulle equazioni lineari alle derivate parziali di $2^{\circ}$ ordine di tipo misto. Accad. Lincei, Rend. (5) 14, 133-247.

Tricomi, F.G., alias Terracini, A., 1940. Algebra per i licei. Principato, Messina.

Tricomi, F.G., 1955. Sullo stato attuale della teoria delle equazioni a derivate parziali. In: Sansone, G. (Ed.), Convegno Internaz. Equazioni Lineari Alle Derivate Parziali. Trieste 25-28 Agosto 1954. Cremonese, Roma, pp. 103-110.

Tricomi, F.G., 1965. Conservatori e progressisti nella matematica di ieri e di oggi. Univ. Politec. Torino. Rend. Semin. Mat. 24 (1964-65), 17-25.

Tricomi, F.G., 1967. La mia vita di matematico attraverso la cronistoria dei miei lavori (Bibliografia commentata 1916-1967). Cedam, Padova.

Tricomi, F.G., 1968. Matematici torinesi dell'ultimo secolo. Atti Accad. Sci. Torino, Cl. Sci. Fis. Mat. Nat. 102 (196768), 253-278.

Tricomi, F.G., 1969. Uno sguardo allo sviluppo della matematica in Italia nel primo secolo dello stato unitario. Univ. Politec. Torino. Rend. Semin. Mat. 28 (1968-69), 63-76.

Tricomi, F.G., 1974. Ricordi di mezzo secolo di vita torinese. Univ. Politec. Torino. Rend. Semin. Mat. 31 (1971-73), 31-43.

Tricomi, F.G., 1975. Guido Fubini e la scienza delle costruzioni. Rend. Mat. VI 8, 103-114.

Tricomi, F.G., 2011. Opere scelte, 2 vols. Unione Matematica Italiana, Bologna. 
Erika Luciano is Associate Professor of Complementary Mathematics (MAT/04) at the Dept. of Mathematics of the University of Turin and Secretary of the Italian Society for the History of Science. Her research activity mostly focuses on social history of mathematics, history of mathematics education, and material history (scientific instruments, collections, libraries, etc.) of mathematics, with special regard to the dynamics of construction and socialization of knowledge during the period 1880-1940, according to international, national and local perspectives. 